\title{
Pattern and Prevalence of Ocular Diseases in Secondary School Students in an Oil Producing Community in Rivers State, Nigeria
}

\author{
Henry Ogbuehi ${ }^{1}$, Elizabeth A Awoyesuku ${ }^{2 *}$ and Chinyere N Pedro Egbe ${ }^{2}$ \\ ${ }^{1}$ Department of Ophthalmology, Federal Medical Centrel, Nigeria \\ ${ }^{2}$ Department of Ophthalmology, University of Port Harcourt Teaching Hospital, Nigeria
}

*Corresponding author: Elizabeth Awoyesuku, Department of Ophthalmology,

Received Date: October 13, 2019

University of Port Harcourt Teaching Hospital, Nigeria.

\begin{abstract}
Aim: This study was carried out to determine the proportion of secondary school students with ocular disorders in two rural communities in Rivers State.

Study design: A cross sectional study Place and Duration of Study: Gokana Local Government area, Rivers State.

Methodology: A cross sectional study on vision screening among secondary school students was carried out in Kegbara-Dere (K-Dere) and Begbara-Dere (B-Dere) Communities in Gokana Local Government Area of Rivers State between. A multistage sampling technique was used to recruit students aged 11 -22 years (mean age $15.7 \pm 2-08$ ) in the 2 community secondary schools. A total of 263 students consisting of 146 (55.5\%) males and $117(44.5 \%)$ females were screened. Statistical package for social science (SPSS 20) was used to analyze the data.

Results: Seventy one of the 263 students had ocular disorders giving a prevalence of $27.0 \%$. Thirty-four (47.9\%) of the students with ocular disorders were in the 14 - 16 years age range. Of the total students with ocular disorders, 45 (63.4\%) were males and $26(36.6 \%)$ were females. Males did not have statistically significant higher prevalence of ocular disorders $(\mathrm{df}=1, \mathrm{P}=0.53)$. There were eight different ocular disorders observed in these students, refractive error (23; 8.7\%) being the commonest followed by suspicious cupped disc (18; 6.4\%). The prevalence of defective color vision and amblyopia were $4.6 \%$ and $1.4 \%$ respectively with male preponderance in defective color vision which was statistically significant (df $=1$, $\mathrm{p}=0.047$ ). No student had a visual acuity $<6 / 18$ or $<3 / 60$ in the better eye. Only $32.4 \%$ ( $n=23$ ) of those with ocular disorder actually complained of ocular symptoms.
\end{abstract}

Conclusion: The prevalence of ocular disorders in this study was $27 \%$ with uncorrected refractive errors ranking highest. School Eye Screening is necessary to reverse this trend.

Keywords: Ocular disorders; Rivers state; Rural communities; Secondary school students

\section{Introduction}

Vision screening in early childhood is a necessity as it enables a child attains his or her full potential; since most persons are visual learners, acquiring approximately 85 percent of all knowledge through vision [1]. it is therefore imperative that a possible visual problem be identified early and treated. However, in typical rural communities such as Kegbara-Dere (K-Dere) and Begbara-Dere (B-Dere) (in South-South Nigeria) where the poverty level is high and majority live on less than one dollar a day [2], access to an eye care specialist is limited and many children would have to continue with any poor eye condition they have into adulthood, sometimes dropping out of school altogether. If severe enough, many vision problems entail a variety of symptoms that greatly affect skills and systems related to learning [3]. It is known that youths from low income families suffer from a disproportionately high prevalence of educationally relevant vision problems and are at high risk of inadequate treatment of vision problem, in which low access to eye care services is a major contributing factor [4].

School eye screening has been acclaimed as one of the best ways to battle childhood blindness and one of the major means of attaining the aim of "Vision 2020 - The Right to Sight" which is a global initiative for prevention of avoidable blindness. The school presents a captive population that can be easily accessed, 
and intervention carried out where possible, as most children are commonly docile by nature $[5,6]$.

About $80 \%$ of blindness in the world are due to avoidable causes [7]. Many of these ocular problems such as trachoma, glaucoma, cataract, refractive error that are amenable to interventional measures are detected through vision screening of selected population such as school children [8-10]. Eye surveys have the potential to promote normal vision, preserve healthy eyes and prevent blindness [11].

Screening is defined as the presumptive identification of individuals at risk in a population likely to be affected by asymptomatic or subclinical condition who can benefit by being further investigated [12]. It is quite disturbing that an estimated 500 000 children become blind each year and in developing countries up to $60 \%$ of them are thought to die within a year of becoming blind [7]. Almost half of all blindness in children-particularly those in the poorest communities is due to avoidable causes that are amenable to cost effective interventions [13]. Considering the concept of Disability--adjusted -life -years (DALY) which is described as a measure of the time lived with a disability and the economic loss incurred during the years, [14] It is therefore very important that children have very good vision considering they have a long time to live as the magnitude of associated economic loss is huge indeed [15].

One effective way to reduce this economic burden is prioritizing school eye survey by relevant authorities because vision screening can also serve as a public health intervention measure [16]. Available report shows that schools with long established tradition of engaging in vision screening have proven to be effective in detecting previously undiagnosed conditions including refractive errors [17].

\section{Materials and Methods}

A population - based cross-sectional Study. The sample size was determined by the Leslie-Kish formula: Araoye MO [18] to be 263 students. A multistage sampling technique was used to select students for this study. Health talk was given on the screening days. Pretested semi - structured questionnaires were administered to the students.

Visual acuity was determined separately for each eye at 6 meters outside the classroom using the Snellen's chart. Where the visual acuity was 6/9 or less, a pinhole was presented for that eye and the test repeated. Ocular examinations were in one of the staff rooms of each school. Both eyes were checked for ocular alignment by Hirschberg Test.

Using ophthalmic loupe and pen torch, adnexa and conjunctiva were checked for abnormalities, the cornea for opacities. Pupil reaction to light was assessed and lens examined for any visible opacities. The anterior chamber depth was also assessed. Direct ophthalmoscopy in a chosen dark spot was done. The state of the retina and optic nerve were assessed.

Students with ocular disorders needing further investigation and treatment were referred to the University of Port Harcourt Teaching Hospital, Port Harcourt with a predesigned referral form.

- Inclusion Criteria

- Students enrolled in both secondary schools

- Enrolled students that parents/guardian gave consent

- 4.2. Exclusion Criteria

- $\quad$ Students above 22 years of age.

- $\quad$ Student whose parents/guardian did not give consent.

\section{Results and Discussion}

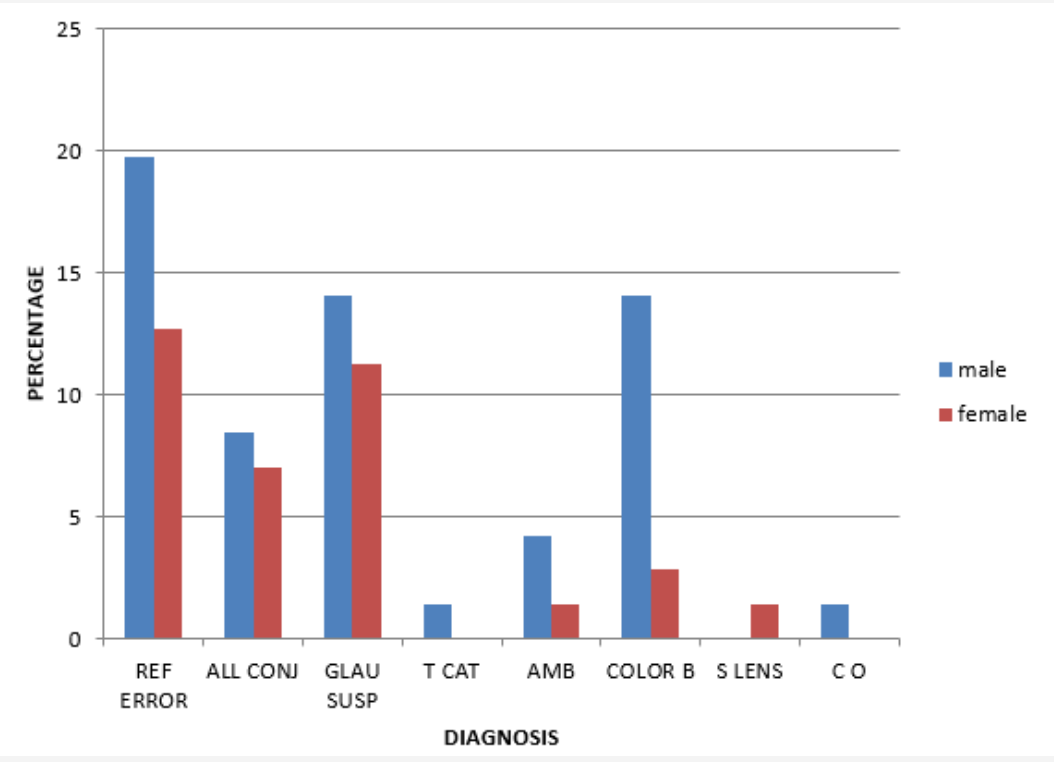

$d f=7, p=0.530$

Figure 1: Ocular Disorders According to Sex. 
A total of 263 students were screened during a two-week period, giving $100 \%$ coverage of the estimated sample size for this study. (Table 1-6) (Figure 1).

Table 1: School distribution of sampled students.

\begin{tabular}{|c|c|c|}
\hline School & $\begin{array}{c}\text { Total population } \\
(\%)\end{array}$ & $\begin{array}{c}\text { Required sample } \\
\text { Examined (\%) }\end{array}$ \\
\hline C SS B-Dere & $700(53.5 \%)$ & $140(53.2 \%)$ \\
\hline CSS K-Dere & $608(46.5 \%)$ & $123(46.8)$ \\
\hline Total & $1308(100 \%)$ & $263(100 \%)$ \\
\hline
\end{tabular}

Key: CSS K - Dere = Community secondary school K - Dere, CSS B Dere $=$ Community secondary school $\mathrm{B}$ - Dere

Table 2: Distribution of Sampled Students According to Class.

\begin{tabular}{|c|c|c|c|}
\hline Class & CSS B-DERE (\%) & CSS K- DERE (\%) & Total (\%) \\
\hline JSS 1 & $26(9.9 \%)$ & $20(7.6 \%)$ & $46(17.5 \%)$ \\
\hline JSS 2 & $25(9.5 \%)$ & $24(9.1 \%)$ & $49(18.6 \%)$ \\
\hline JSS 3 & $24(9.1 \%)$ & $21(8.0 \%)$ & $45(17.1 \%)$ \\
\hline SS 1 & $23(8.7 \%)$ & $19(7.3 \%)$ & $42(16.0 \%)$ \\
\hline SS 2 & $22(8.4 \%)$ & $20(7.6 \%)$ & $42(16.0 \%)$ \\
\hline SS 3 & $20(7.6 \%)$ & $19(7.2 \%)$ & $39(14.8 \%)$ \\
\hline TOTAL & $140(53.2 \%)$ & $123(46.8 \%)$ & $\begin{array}{c}263 \\
(100.0 \%)\end{array}$ \\
\hline
\end{tabular}

Key: JSS = Junior Secondary School, SSS = Senior Secondary School

Table 3: Age and Sex Distribution of Sampled Students.

\begin{tabular}{|c|c|c|c|}
\hline $\begin{array}{c}\text { Age Group in } \\
\text { Years }\end{array}$ & Male (\%) & Female (\%) & Total (\%) \\
\hline $11-13$ & $18(6.8 \%)$ & $23(8.8 \%)$ & $41(15.6 \%)$ \\
\hline $14-16$ & $61(23.2 \%)$ & $59(22.4 \%)$ & $120(45.6 \%)$ \\
\hline $17-19$ & $61(23.2 \%)$ & $34(12.9 \%)$ & $95(36.1 \%)$ \\
\hline $20-22$ & $6(2.3 \%)$ & $1(0.4 \%)$ & $7(2.7 \%)$ \\
\hline Total & $146(55.5 \%)$ & $117(44.5 \%)$ & $263(100 \%)$ \\
\hline
\end{tabular}

$(\mathrm{df}=3, \mathrm{p}=0.032)$

Mean age $=15.7$ years \pm 2.08

Table 4: Ocular Symptoms among the Students.

\begin{tabular}{|c|c|c|}
\hline Symptoms & Frequency & $\%$ \\
\hline Difficulty seeing far & 11 & 4.2 \\
\hline Itching & 11 & 4.2 \\
\hline Eye pain & 1 & 0.4 \\
\hline No complaint & 240 & 91.2 \\
\hline Total & 263 & 100 \\
\hline
\end{tabular}

Table 5: Types and Prevalence of Ocular Disorders.

\begin{tabular}{|c|c|c|}
\hline Ocular Disorders & Frequency & Percentage \\
\hline Refractive Error & 23 & 8.7 \\
\hline Suspicious disc & 18 & 6.8 \\
\hline Color Blindness & 12 & 4.6 \\
\hline Allergic Conjunctivitis & 11 & 4.2 \\
\hline Amblyopia & 4 & 1.5 \\
\hline Traumatic Cataract & 1 & 0.4 \\
\hline Subluxated Lens & 1 & 0.4 \\
\hline Corneal Opacity & 1 & 0.4 \\
\hline Normal & 192 & 73 \\
\hline Total & 263 & 100 \\
\hline
\end{tabular}

Table 6: Ocular Diagnosis According to Age Group.

\begin{tabular}{|c|c|c|c|c|c|}
\hline \multicolumn{6}{|c|}{ Age Group (In Years) } \\
\hline Diagnosis & $11-13$ & $14-16$ & $17-19$ & $20-22$ & Total \\
\hline $\begin{array}{c}\text { REF } \\
\text { ERROR }\end{array}$ & $2(0.8 \%)$ & $12(4.6 \%)$ & $7(2.7 \%)$ & $2(0.8 \%)$ & $23(8.7 \%)$ \\
\hline ALL CONJ & $3(1.0 \%)$ & $5(1.9 \%)$ & $3(1.0 \%)$ & 0 & $11(4.2 \%)$ \\
\hline SUSP DISC & $4(1.5 \%)$ & $9(3.4 \%)$ & $5(1.8 \%)$ & 0 & $18(6.8 \%)$ \\
\hline T CAT & 0 & $1(0.4 \%)$ & 0 & 0 & $1(0.4 \%)$ \\
\hline AMB & $2(0.8 \%)$ & $2(0.8 \%)$ & 0 & 0 & $4(1.5 \%)$ \\
\hline COLOR B & $1(0.4 \%)$ & $3(1.0 \%)$ & $7(2.7 \%)$ & $1(0.4 \%)$ & $12(4.6 \%)$ \\
\hline S LENS & 0 & $1(0.4 \%)$ & 0 & 0 & $1(0.4 \%)$ \\
\hline $\mathrm{CO}$ & 0 & $1(0.4 \%)$ & & 0 & $1(0.4 \%)$ \\
\hline Normal & $29(11 \%)$ & $\begin{array}{c}86 \\
(32.7 \%) \\
\end{array}$ & $\begin{array}{c}73 \\
(27.8 \%) \\
\end{array}$ & $4(1.5 \%)$ & $\begin{array}{c}192 \\
(73.0 \%) \\
\end{array}$ \\
\hline Total & $\begin{array}{c}41 \\
(15.5 \%)\end{array}$ & $\begin{array}{c}120 \\
(45.6 \%)\end{array}$ & $\begin{array}{c}95 \\
(36.0 \%)\end{array}$ & $7(2.7 \%)$ & $\begin{array}{c}263 \\
(100.0 \%)\end{array}$ \\
\hline
\end{tabular}

$(\mathrm{df}=21, \mathrm{p}=0.72)$

Key: Ref error= Refractive error, ALL CONJ - Allergic Conjunctivitis, SUSP DISC - Suspicious disc, T CAT - Traumatic Cataract, AMB Amblyopia, COLOR B - Color Blindness, S LENS - Subluxated Lens, C O - Corneal Opacity.

\section{Discussion}

This study found the prevalence of ocular disorders in secondary school students in B-Dere and Kegbara-Dere communities to be $27.0 \%$. This is similar to a study by Alakija W [19] involving secondary school students in Benin City where a prevalence of $25.6 \%$ for females and $19.9 \%$ for males was found. Other studies in Nigeria involving secondary school students by Ajaiyeoba $\mathrm{AI}$, et al. [15], Adegbehingbe BO, et al. [16], and Abah ER, et al. [28] found a prevalence of $19.5 \%, 22.5 \%$, and $22.6 \%$, respectively. While Adio AO, et al. [21] found a prevalence of 9.4\% among primary school pupil aged 5-15 years in Yenagoa, Bayelsa state. Wedner SH, et al. [22] in Tanzania reported a prevalence of $6.9 \%$ in a study among secondary school students. A strict comparison of these studies is difficult as there are some differences in the age groups studied, the geographic location, the case definition of eye disorders and sample size. In this study, the cut off level of defective vision was visual acuity $<6 / 6$ which was the same in the study by Alakija AI, et al. [19] while Adegbehingbe BO, et al. [16] used $<6 / 9$ as the cut off. In this study the age range was from 11 years to 22 years (mean age 15.7 years \pm 2.08 ) which contrasts with Abah ER, et al. [20] (7-15 years).

The difference in sample size could also account for the differences in prevalence; in Ajaiyeoba AI, et al. [15], Adio AO, et al. [20], and Adegbehingbe BO, et al. [16] studies large sample sizes (1144, 1,242 and 1707 respectively) were used, compared to the small sample size of this study ( $n=263$ ). The poor accessibility to eye care facilities in these rural communities could also account for the higher prevalence as most of the people in these communities are yet to fully utilize the existing community outreach program of the Department of Ophthalmology, University of Port Harcourt Teaching Hospital, which is often times disrupted because of incessant communal clashes. 
In this study, (Figure 1) males had a higher prevalence (17.1\%) of ocular disorders compared to females (9.9\%). This difference was however not statistically significant $(\mathrm{df}=8, \mathrm{p}=0.42$ ). This contrasts with the studies by Ajaiyeoba AI, et al. [15] and Osunde EA, et al. [23] who reported a higher prevalence of ocular disorders among females, though more females were represented in their sample sizes, comparatively the finding of more ocular disorders among males in this study may also be due to their higher representation in the sample size. Most ocular disorders (Table 6) occurred in the 14-16-year age group (12.9\%) which was not statistically significant $(\mathrm{df}=24, \mathrm{p}=0.67$ ), followed by the 17-19-year age group. This differs from the finding by Ajaiyeoba AI, et al. [15] who reported the highest prevalence among the 10-14-year age group, followed by the 15-19-year age group; again this variance may be due to difference in the age range and the age groups with largest sample size.

Only $32.4 \%(n=23)$ of those with ocular disorders actually complained of ocular symptoms this agrees with other studies by Alakija W [19] and Ajaiyeoba AI, et al. [15], where very few had ocular symptoms compared to disorders. The common ocular symptoms were 'difficulty seeing far' and itching. The most prevalent ocular disorder in this study was refractive error, followed by glaucoma suspect and color blindness. Similarly, Abah ER, et al. [20] also reported refractive error as the commonest ocular disorder followed by allergic conjunctivitis. However, the study by Ajaiyeoba AI, et al. [15] and Adegbehingbe BO, et al. [16] reported vernal conjunctivitis as the most common ocular disorder followed by refractive error.

The prevalence of refractive error in this study was $8.7 \%$, which falls within the WHO range of $2-10 \%$ worldwide, [24]. most of the students $(73.9 \% \mathrm{n}=17)$ with refractive error had small refractive error (presenting VA 6/9 bilaterally). The observed prevalence of $8.7 \%$ in this study is lower than the prevalence of $13.5 \%$ and $13.9 \%$ reported in studies by Adegbehingbe BO, et al. [16] and Osunde ER, et al. [23] respectively. It was however closer to figures reported by Naido KS, et al. [25] in South Africa and that by Murthy (6.4\%) Murthy GV, et al. [26] in India. The prevalence of suspicious disc of glaucoma (6.8\%) in this study was higher than that reported by other studies $[16,20]$. This is about three times that reported by Pedro Egbe CN, et al. [27] in a study on the prevalence of glaucoma suspects in Ahoada East LGA Rivers state. This may be a true reflection of the disease in the communities studied.

The prevalence of congenital color blindness in this study was $4.6 \%$, with a male preponderance which was statistically significant $(\mathrm{df}=1, \mathrm{p}=0.047)$. This is expected considering that congenital defective color vision has X-linked pattern of inheritance, and may also be due to the higher representation of males in the sample. A lower prevalence of defective color vision has been reported by other workers $[28,21,20]$. The lower prevalence(4.2\%) of allergic conjunctivitis in this study as compared to other studies may be due to the geographic location of these communities in the mangrove belt, where it rains all year round with few period of dryness and the age range falls into the group with lower prevalence in the natural history of allergic conjunctivitis. This finding agrees with the prevalence of allergic conjunctivitis reported by Adio AO, et al. [21] in study involving primary school pupils in nearby state of the same geographic zone.

The prevalence of Amblyopia was $1.5 \%(n=4)$ and was found within the range of 13-16 years in this study. This finding at late childhood can be explained by paucity of eye care service in the communities before the advent of the Outreach by University of Port Harcourt Teaching Hospital Ophthalmology Department. Subluxated lens, cataract and corneal opacity all shared a prevalence of $0.4 \%$; they were not visually significant as visual acuity in the subluxated lens and the cataract (immature) was 6/9 which improved with pinhole to $6 / 6$. Though subsistence farming is the main economic activity in both communities, the subluxated lens and cataract were due to domestic violence while for the corneal opacity (which was away from pupillary axis), a clear history could not be obtained, and the student was not aware of the pathology.

In this study no case of squint was observed which contrasts with the finding by Adio AO, et al. [21] (prevalence of 0.4\%) in her study involving similar geographic zone, this may be explained by the difference in sample size.

The finding of students in their early twenties in this study, is not uncommon, this can be observed in other studies in Nigeria; $[15,16,20]$ and Tanzania $[22,29-39]$. This late placement of children in schools may be dependent on the economic and educational status of their parents or guardians.

\section{Limitations}

This study was carried out limited resources; availability of portable slit lamp and Perkins applanation tonometer would have been of immense value in the clinical assessment of the sample population.

\section{Conclusion}

The prevalence of ocular disorders in this study was $27 \%$ with uncorrected refractive errors ranking highest. School Eye Screening is necessary to reverse this trend.

\section{Acknowledgement}

None.

\section{Conflict of Interest}

Authors have declared that no conflict of interests exists.

\section{References}

1. Yorston D (1991) Measles and Childhood Blindness. Community Eye Health Journal 8: 2-4

2. World Bank Nigeria: Country Brief, Nigeria.

3. Pratab VB Lai HB (1989) Pattern of Pediatric Ocular Problems in North India. Indian J Ophthalmol 37(4): 171-172.

4. Gilbert C (2005) Control of Childhood Blindness Manual for Community Eye Health Module. Control of Disease. West African College of Surgeons, Nigeria. 
5. Wormald R (1998) Screening in Ophthalmology. In: The Epidemiology of Eye Diseases. Gordon J Johnson, Darwin C Minassian, Robert Weale (eds), Lippincott Raven Publishers, 4: 83-100.

6. Ganz ML, Xuan Z, Hunter DG (2006) Prevalence and Correlates of Children's Diagnosed Eye and Vision Conditions. Ophthalmology 113(12): 2298-2306

7. World Health Organization (2000) Preventing Blindness in Children, Switzerland, Ppt 1-40.

8. Faderin MA, Ajaiyeoba AI (2001) Refractive errors in Primary School Children in Nigeria. Nigerian Journal of Ophthalmology 9(1): 10-14.

9. Wedner S, Dineen B (2003) Refractive errors. Trop Doc 33: 207-209.

10. Abubakar S Ajaiyeoba AI (2001) Screening for Eye Disease in Nigeria School Children. Nig J Ophthalmol 9: 6-9.

11. Johnson GJ, Foster A (2003) Prevalence, Incidence and Distribution of Visual Impairment. Epidemiology of Eye Disease. In: Johnson GJ, Minassian DC, Weale RA, West SK (eds), Arnold publishers, London, Ppt 3-28.

12. Wilson JM, Junger YG (1986) Screening for Disease, World Health Organization. Switzerland.

13. World Bank (1993) World Development Report 1993: Investing in Health. Oxford University Press. New York, USA.

14. World Health Organization (1999) Childhood Blindness Prevention. India.

15. Ajaiyeoba AI Isawumi MA Adeoye AO Oluleye TO (2007) Pattern of Eye Diseases and Visual Impairment among Students in Southwestern Nigeria. Int Ophthalmol 27(5): 287-289.

16. Adegbehingbe BO, Oladehinde MK, Majemgbasan TO, Onakpoya HO, Osagiede EO (2005) Screening of Adolescents for Eye Diseases in Nigerian High Schools. Ghana Med J 39(4): 138-142.

17. Yawn BP, Lydick EG, Epstein R, Jacobsen SJ (1996) Is School Vision Screening Effective? J Sch Health 66(5): 171-175.

18. Araoye MO (2003) Subjects Selection. In: Research Methodology with Statistics for Health and Social Sciences. Nathadex Publishers, Ilorin. Ppt 115-129.

19. Alakija W (1995) Poor Distant Vision in Post-Primary Schools in Benin City, Nigeria. Public Health 95(3): 165-170.

20.Abah ER, Oladigbolu KK, Samaila E, Gani Ikilama A (2011) Ocular Disorders in Children in Zaria Children's School. Niger J Clin Pract 14(4): 473-476.

21. Adio AO, Opubiri RI (2011) Pattern of Eye Diseases among Primary School Children in Bayelsa State. Afr j educ res admin 4(2): 72-79.

22. Wedner SH, Ross DA, Todd J, Anemona A, Balira R, et al. (2002) Myopia in secondary school students in Mwanza City, Tanzania: The need for a National Screening Program. Br J Ophthalmol 86(11): 1200-1206.

23. Osunde EA, Raymond O, Adio AO (2010) Refractive Errors among a young population in an Urban Secondary School in South-Southern Nigeria. PMJ 4(3): 228-236.
24. (2008) Global Magnitude of Visual Impairment caused by uncorrected Refractive Errors in 2004: Bull WHO 86 (1): 1-7.

25. Naidoo KS, Raghunanadan A, Mashige Kp, Govender P, Holden BA, et al. (2003) Refractive Error and Visual Impairment in African Children in South Africa. Invest Ophthalmol Vis Sci 44(9): 374-380.

26. Murthy GV, Gupta SK, Ellwein LB, Munoz SR, Pokharel GP, et al. (2002) Refractive Error in Children in an Urban Population in New Delhi. Invest Ophthalmol Vis Sci 43(3): 623-631.

27. Pedro Egbe CN, Waziri Erameh JM (2009) Prevalence of Glaucoma Suspects and Pattern of Intra-ocular Pressure (IOP) Distribution in Ahoada-East Local Government Area of Rivers State. Port Harcourt Medical Journal 4 (1): 17-22.

28. Tabansi PN (2007) Screening for Ocular anomalies in Lower Primary School Children in Port Harcourt City. Dissertation for the award of a Fellowship of the West African College of Physicians in Pediatrics, Nigeria.

29. The Nigeria National Blindness and Visual Impairment Study Group. Prevalence of Blindness and Visual Impairment in Nigeria: The National Blindness and Visual Impairment Survey, Invest. Ophthalmol. Vis. Sci 2009: 50(5):2033-39

30. Castanes MS (2003) The Underutilization of Vision Screening for Amblyopia, Optical Anomalies and Strabismus among Preschool Age Children. Binocul Vis Strabismus Q 18(4): 217-223.

31. Shrestha RK, Joshi MR, Ghising R, Pradhan P, Shakya S, et al. (2006) Ocular Morbidity among Children Studying in Private Schools of Kathmandu Valley: A Prospective Cross-Sectional Study. Nepal Med Coll J 8(1): 43-46.

32. Gilbert CE, Ellwein LB (2008) Prevalence and Causes of Functional Low Vision in School-age Children: Results from Standardized Population Surveys in Asia, Africa, and Latin America. Invest Ophthalmol Vis Sci 49(3): 877-881.

33. Okosa MC (1995) Ocular Health Status of Post Primary School Children in Enugu State, Nigeria: Dissertation Submitted for the National Fellowship Diploma of the Postgraduate Medical College of Nigeria.

34. Gogato PM, Desphponde M, Sudrik S, Kishore H, Taras S, et al. (2007) Changing pattern of Childhood Blindness in Maharashtra, India. Br J Ophthalmol 91(1): 8-12.

35. Kello A B, Gilbert CE (2003) Causes of Severe Visual Impairment and Blindness in Children in Schools for the Blind in Ethiopia. Br J Ophthalmol 87(5): 526-530.

36. Gilbert C, Foster A (2001) Childhood blindness in the context of vision 2020- The "Right to Sight". Bull World Health Organ 79(3): 227-232.

37. Woddell K (2000) Spherical Refraction for General Eye Workers. Community Eye Health 13(33): 6-8.

38. Presian MW, Norak A (1996) Baltimore vision screening project. Ophthalmology 103(1): 105-109.

39. Araoye MO (2003) Subjects Selection. In: Research Methodology with Statistics for Health and Social Sciences; Nathadex Publishers, Ilorin. Ppt 115-129. 